\title{
Evidence summary on the timing and frequency of screening for perinatal depression
}

\author{
Shafeng Jia ${ }^{1 \#}$, Mengwei Zhi" ${ }^{2 \#}$, Jia Liu ${ }^{1}$, Jia Liu ${ }^{3}$, Ling Jiang ${ }^{3}$, Yueqin Zhu ${ }^{3}$ \\ ${ }^{1}$ Department of Obstetrics, Suzhou Municipal Hospital, The Affiliated Suzhou Hospital of Nanjing Medical University, Suzhou, China; ${ }^{2}$ Department \\ of Hepatobiliary Surgery, Suzhou Municipal Hospital, The Affiliated Suzhou Hospital of Nanjing Medical University, Suzhou, China; ${ }^{3}$ Department \\ of Nursing, Suzhou Municipal Hospital, The Affiliated Suzhou Hospital of Nanjing Medical University, Suzhou, China \\ Contributions: (I) Conception and design: J Liu, J Liu; (II) Administrative support: M Zhi; (III) Provision of study materials or patients: L Jiang; (IV) \\ Collection and assembly of data: S Jia, Y Zhu; (V) Data analysis and interpretation: S Jia; (VI) Manuscript writing: All authors; (VII) Final approval of \\ manuscript: All authors. \\ \#These authors contributed equally to this work. \\ Correspondence to: Jia Liu. Department of Obstetrics, Suzhou Municipal Hospital, The Affiliated Suzhou Hospital of Nanjing Medical University, \\ Suzhou 215000, China. Email: 2271634769@qq.com; Jia Liu. Department of Nursing, Suzhou Municipal Hospital, The Affiliated Suzhou Hospital \\ of Nanjing Medical University, Suzhou 215000, China. Email: liujia_sz@163.com.
}

\begin{abstract}
Background: This study sought to search, evaluate, and summarize the best evidence about the time and frequency of screening for perinatal depression (PND).

Methods: The UpToDate, Scottish Intercollegiate Network, National Institute for Health and Care Excellence, National Guideline Clearinghouse, Guidelines International Network, BMJ Best Practice, Cochrane Library, Embase, Campbell Collaboration, CINAHL, Joanna Briggs Institute Library, Medline, CNKI, Wanfang, VIP, and CBM databases were searched to retrieve relevant articles.

Results: A total of 9 articles were included in the meta-analysis, comprising 2 guidelines, 1 expert consensus, 1 evidence summary, 3 systematic reviews, and 2 clinical decisions. A total of 11 articles of best evidence were collected. The evidence was mainly related to the two aspects of screening time and frequency. Conclusions: There is abundant evidence on the best screening time for and frequency of PND; however, some evidence was from foreign evidence-based resources. Local clinical conditions need to be considered at the time of application.
\end{abstract}

Keywords: Perinatal depression (PND); screening time; screening frequency; evidence-based nursing

Submitted Aug 17, 2021. Accepted for publication Oct 22, 2021.

doi: 10.21037/apm-21-2675

View this article at: https://dx.doi.org/10.21037/apm-21-2675

\section{Introduction}

Perinatal depression (PND), which includes antenatal depression (AND) and postpartum depression (PPD), refers to mood disorders occurring from pregnancy to within 1 year postpartum for which the core symptoms are depression and anhedonia, accompanied by low interest, decreased attention, depression, and low self-evaluation symptoms (1). The incidence of PND worldwide is $12.4-38.8 \%$ (2). An Australia retrospective study shows the incidence of antenatal and postnatal depressive symptoms was $6.2 \%$ and $3.3 \%$, respectively (3). In mainland China, the incidence of PND is $16.3 \%$, among which, $19.7 \%$ is AND, and is $14.8 \%$ is PPD. PND has been on the rise in the past decade (4). Studies have shown that PND is not conducive to the physical and mental health of mothers and infants, affects family relationships, and sustained PND also causes short- and long-term adverse effects on infants' cognitive, personality, emotion, and behavior development (5-7). In severe cases, patients' may even commit suicide or infanticide (8-10), which places a heavy burden on families and society. PND interacts 
with pregnancy complications, smoking, social support, and other factors that jointly lead to adverse pregnancy outcomes. Thus, targeted preventive measures, such as specially trained health-care personnel, need to be implemented to provide appropriate help and guidance to women via timely screening and improve the mental health status of maternal women (11). According to the literature review, there is no uniform standard for the screening time of PND. Thus, best time for PND screening (e.g., prenatal or postpartum, or continuous multiple screenings) requires further study $(12,13)$. Indeed, there is very little evidence on the best timing and frequency of PND screening. Thus, conclusions from a wider range of studies are important for clinical practice. This study sought to provide a scientific and effective decision basis for the time and frequency of PND screening through the retrieval, summary and analysis of domestic and foreign evidence.

\section{Methods}

\section{Question identification}

The question was identified using the Johns Hopkins's evidence-based nursing practice problem development tool and the PICO principle. The formed initial question was as follows: $\mathrm{P}$ (population): adult maternal women; I (intervention): Timing and frequency of PND screening; $\mathrm{C}$ (comparison): Current time and frequency of routine screening for PND in adult maternal women; O (outcome): PND screening positive rate, screening positive referral rate, and Edinburgh postnatal depression scale (EPDS).

\section{Retrieval strategies}

The following Chinese search terms were used: "gravida/ puerpera/maternal/perinatal stage/antenatal/postpartum/ puerperium", "screening/assessment/management", and "depression/Perinatal depression/anxiety/psychogeny/ Edingburgh postnatal depression scale". The following English search terms were used: "pregnant woman/ puerperal/perinatal/antepartum/postpartum/puerperium”, "screening/assessment/management", and "depression/ perinatal depression/anxiety/mood disorders/Edinburgh Postnatal depression scale". The following databases were searched: UpToDate, Scottish Intercollegiate Network (SIGN), National Institute for Health and Care Excellence (NICE), National Guideline Clearinghouse (NGC), Guidelines International Network (GIN), BMJ
Best Practice, Cochrane Library, Embase, Campbell Collaboration, CINAHL, JBI Library, Medline, China National Knowledge Infrastructure (CNKI), Wangfang, cqvip.com, and Chinese Biomedical Literature Database. Guidelines, expert consensuses, evidence summaries, clinical decision making articles, systematic reviews, and meta-analyses were included in this study.

\section{Literature inclusion and exclusion criteria}

To be eligible for inclusion in this study, the articles had to meet the following inclusion criteria: (I) the subjects comprised adult maternal women ( $\geq 18$ years old); (II) the research examined the screening, assessment, or management of PND; (III) the article was published in the Chinese or English language; and (IV) the article was published between January 2016 and March 12, 2021. There were no restrictions in relation to the research environment. Articles were excluded from the study if they met any of the following exclusion criteria: (I) the article was a direct translation, or repeatedly included foreign guidelines or expert consensuses, such as guideline interpretations; (II) the article only comprised a published abstract; (III) the full text was not available; and/or (IV) the article failed to pass the literature quality evaluation.

\section{Literature quality evaluation criteria}

Clinical Guidelines were evaluated with Appraisal of Guidelines for Research and Evaluation, AGREE II (14). The scores of AGREE II ranges from 1-7, with 1 being "strongly disagree" and 7 being "strongly agree". Guidelines were included or excluded based on the results of a standardized evaluation. The systematic review and expert consensus articles were evaluated using the evaluation criteria of the Australia JBI Evidence-based Health Care Center (15). CASE list was used to evaluate the evidence summary article (16). To evaluate the clinical decisions, they were traced back to the original literature based on the evidence, and corresponding evaluation criteria were selected according to the type of the original literature.

\section{Literature quality evaluation process}

Two researchers trained by the JBI Collaborating Center for Evidence-based Care at Fudan University independently evaluated the articles in accordance with the above criteria. 
Guideline website: NICE ( $n=16), \operatorname{NGC~}(n=61), \operatorname{SIGN~}(n=8), \operatorname{GIN}(n=11)$ Database: UpToData $(n=150)$, BMJ Best Practice $(n=5)$, JBI Library $(n=6)$, Cochrane Library $(n=234)$, Campbell Collaboration $(n=13)$, Medline $(n=25)$, Embase $(n=167)$, CINAHL $(n=58))$, CNKI $(n=69)$, Wangfang $(n=63)$, cqvip.com $(n=3)$,

Chinese Biomedical Literature Database $(n=15)$

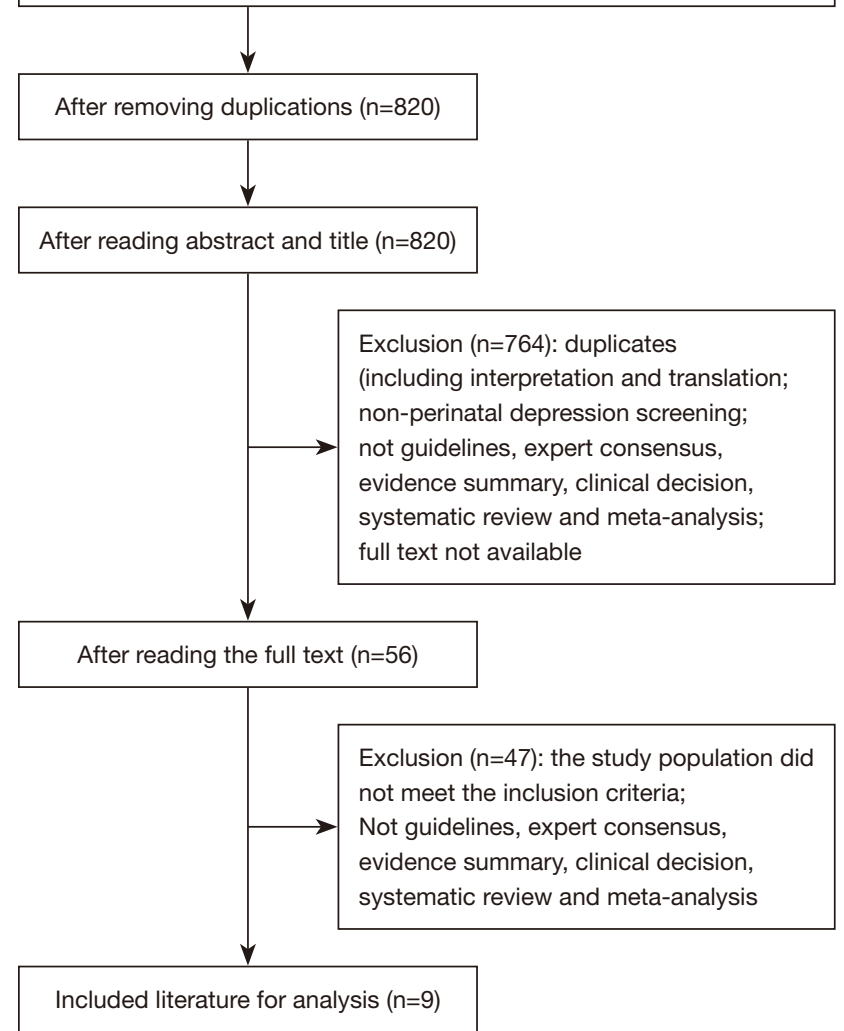

Figure 1 Screening flow chart for articles.

The researchers discussed the evaluation results of each article together. If a dispute arose, the issue was discussed with a 3 rd, researcher who decided whether to include or exclude the article. If there were any conflicts about the conclusions drawn for different sources of evidence, the principle of "evidence-based evidence first, high-quality evidence first, the latest published evidence first" was adopted.

\section{Evidence extraction and summary}

The data were extracted and cross-checked by the two researchers using a pre-developed "General information on the included literature" form. The extracted data included the author, the subject, evidence type, publication date, and source database.

\section{Results}

\section{General characteristics of the included articles}

Ultimately, a total of 9 articles were included, including 2 guidelines (17,18), 1 expert consensus (19), 1 evidence summary (20), 3 systematic reviews (21-23), and 2 clinical decisions $(24,25)$. The literature screening flow chart is shown in Figure 1, and the general characteristics of the included articles are set out in Table 1.

\section{Quality evaluation results of the included articles}

Results of quality evaluation of the guidelines

Two guidelines were included from the NICE (17) and the American College of Obstetricians and Gynecologists (18). AGREE II was used to evaluate the guidelines (Table 2).

\section{Quality evaluation results of expert consensus}

One expert consensus was included (19). The evaluation results of the items were all "yes" except for the "Whether the points of view proposed are inconsistent with the previous literatures" item. The overall quality of the study was high; thus, it was included.

\section{Results of the quality evaluation of the evidence summary}

One evidence summary was included (20). The evaluation result of the "Whether the reviewer or editor of the evidence summary is clear and transparent" item was "no". The evaluation result of the "Whether the retrieval method is transparent and comprehensive", and "Whether the summary of evidence avoids potential bias" items were "partly yes". The evaluation results for all the other items were "yes". The overall quality of the evidence summary was high; thus, it was included.

\section{Quality evaluation results of the systematic reviews}

Three systematic reviews were included. In the study of O'Connor et al. (21), the evaluation results of the items were all "yes" except that for the "Whether the database or resources of the retrieved literature are sufficient" item, which was "unclear". In the study of Biaggi et al. (22), the evaluation results of the "Whether the literature quality evaluation criteria adopted are appropriate" and "Whether 2 or more reviewers independently completed the literature quality evaluation" items were "unclear". The evaluation result of the "Whether the method of merging studies is appropriate" item was "no". The evaluation results of all 
Table 1 General information of included articles

\begin{tabular}{|c|c|c|c|c|}
\hline Included article & Topic & Source & Type of evidence & Year \\
\hline $\begin{array}{l}\text { American College of Obstetricians and } \\
\text { Gynecologists (18) }\end{array}$ & PND screening & ACOG & Clinical guideline & 2018 \\
\hline $\begin{array}{l}\text { Psychosomatic Health Group of Chinese } \\
\text { Preventive Medicine Association (19) }\end{array}$ & Maternal mental health management & CNKI & Expert consensus & 2019 \\
\hline O’Connor et al. (21) & Preventive measures for PND & Embase & Systematic review & 2019 \\
\hline Biaggi et al. (22) & $\begin{array}{l}\text { Diagnosis of prenatal anxiety and } \\
\text { depression risk }\end{array}$ & Embase & Systematic review & 2016 \\
\hline Martínez-Borba et al. (23) & $\begin{array}{l}\text { Application of information and } \\
\text { communication technology in PND } \\
\text { screening }\end{array}$ & CINAHL & Systematic review & 2018 \\
\hline Lockwood et al. (25) & $\begin{array}{l}\text { Prenatal examination: mid-trimester and } \\
\text { late pregnancy }\end{array}$ & UpToDate & Clinical decision & 2020 \\
\hline
\end{tabular}

PND, perinatal depression.

Table 2 Quality of included guidelines

\begin{tabular}{lcccccccc}
\hline & \multicolumn{5}{c}{ Standardized scores in each area } & & \\
\cline { 2 - 7 } Guidelines & $\begin{array}{c}\text { Scope and } \\
\text { purpose }\end{array}$ & $\begin{array}{c}\text { Involved } \\
\text { personnel }\end{array}$ & $\begin{array}{c}\text { Preciseness } \\
\text { of guideline } \\
\text { development }\end{array}$ & $\begin{array}{c}\text { Clarity of } \\
\text { presentation }\end{array}$ & $\begin{array}{c}\text { Applicability } \\
\geq 60 \% \text { field } \\
\text { Independence } \\
\text { of writing }\end{array}$ & $\begin{array}{c}\leq 30 \% \text { field } \\
\text { number (n) }\end{array}$ \\
\hline NICE & $100 \%$ & $76.39 \%$ & $88.10 \%$ & $93.06 \%$ & $88.89 \%$ & $77.78 \%$ & 6 & 0 \\
ACOG & $100 \%$ & $65.28 \%$ & $69.05 \%$ & $94.44 \%$ & $59.26 \%$ & $80.56 \%$ & 5 & 0 \\
\hline
\end{tabular}

the other items were "yes". In the study of Martínez-Borba et al. (23), the evaluation result of the "Whether the database or resources of the retrieved literature are sufficient" and "Whether the possibility of publication bias are assessed" items were "no". The evaluation results of the "Whether the literature quality evaluation criteria adopted are appropriate", "Whether 2 or more reviewers independently complete the literature quality evaluation", and "Whether the method of merging studies is appropriate" items were "unclear". The evaluation results of all the other items were "yes". The overall quality of the systematic evaluations was high; thus, all articles were included.

\section{Quality evaluation results of the clinical decisions}

A total of two clinical decisions were included $(24,25)$. One of the pieces of evidence was cited. Evidence came from a systematic review (26). The evaluation results for each item in the systematic evaluation were "yes". The research designs were complete and the overall quality was high; thus, these articles were included.

\section{Summary of evidence}

In this paper, a total of 14 pieces of evidence about the time and frequency of PND screening were extracted from 9 included articles, and 11 pieces of evidence were included for grading after eliminating duplicates. The Australian JBI Evidence-based Health Care Centre Evidence Recommendation Level System (2014 edition) was used to grade the included evidence. According to 
Table 3 Best evidence on the timing and frequency of screening for PND

\begin{tabular}{|c|c|c|c|c|}
\hline Item & Evidence description & Source & $\begin{array}{l}\text { Evidence } \\
\text { level }\end{array}$ & $\begin{array}{l}\text { Recommendation } \\
\text { level }\end{array}$ \\
\hline \multirow[t]{4}{*}{$\begin{array}{l}\text { Screening } \\
\text { time }\end{array}$} & $\begin{array}{l}\text { 1. Routine screening for depression is recommended throughout the perinatal } \\
\text { period (23) }\end{array}$ & CINAHL & $1 a$ & A \\
\hline & $\begin{array}{l}\text { 2. Maternal mental health screening should be conducted at least in the } \\
1 \text { st trimester (before } 13+6 \text { weeks), 2nd trimester (14-27+6 weeks), 3rd trimester } \\
\text { ( } 28 \text { weeks and beyond) and } 42 \text { days after delivery (19) }\end{array}$ & CNKI & $5 b$ & A \\
\hline & $\begin{array}{l}\text { 4. It is recommended that postpartum patients be screened at least once, and } \\
\text { the ideal time for screening is } 4-8 \text { weeks after delivery ( } 24)\end{array}$ & UpToDate & $1 \mathrm{a}$ & $A$ \\
\hline & $\begin{array}{l}\text { 5. Of all contacts after the 1st primary care or appointment, health visitors and } \\
\text { other health-care professionals who have regular contact with women during } \\
\text { pregnancy and postpartum (the 1st year after delivery) should consider: asking } \\
2 \text { depression identification questions and administering the GAD-2 as part of a } \\
\text { general discussion about their mental health and wellbeing, and using EPDS or } \\
\text { PHQ-9 as part of the assessment (17) }\end{array}$ & NICE & $5 b$ & $\mathrm{~B}$ \\
\hline \multirow[t]{4}{*}{$\begin{array}{l}\text { Screening } \\
\text { frequency }\end{array}$} & $\begin{array}{l}\text { 6. Women should be assessed for symptoms of depression and anxiety at least } \\
\text { once during pregnancy or postpartum, using proven screening tools (18) }\end{array}$ & $A C O G$ & $5 b$ & $\mathrm{~B}$ \\
\hline & $\begin{array}{l}\text { 7. For women with high-risk factors, the number of mental health assessments } \\
\text { should be increased, as appropriate, during preparation and during } \\
\text { pregnancy (18) }\end{array}$ & CNKI & $5 b$ & $A$ \\
\hline & $\begin{array}{l}\text { 8. When women show anxiety or depression at } 1 \text { or } 2 \text { points in time, } 1 \text { screening } \\
\text { is not enough (22) }\end{array}$ & Embase & $3 e$ & $A$ \\
\hline & $\begin{array}{l}\text { 9. Conducting more evaluations during pregnancy and childbirth increases the } \\
\text { accuracy of predicting the occurrence of PPD. If clinical manifestations are } \\
\text { present, assessments can be repeated at any time during pregnancy and within } \\
\text { the 1st year of delivery (19) }\end{array}$ & CNKI & $5 b$ & $\mathrm{~B}$ \\
\hline
\end{tabular}

PND, perinatal depression.

the different types of research design, the evidence levels ranged from 1-5, and according to the reliability and rigor of the research design, the evidence levels were divided into A recommendation (strong recommendation) and $\mathrm{B}$ recommendation (weak recommendation) (see Table 3).

Screening time were recommended at least in the 1 st trimester (before $13+6$ weeks), 2 nd trimester (14-27+6 weeks), 3rd trimester (28 weeks and beyond) and 42 days after delivery, and should end no later than 1 year postpartum.

\section{Discussion}

PND is an important disease affecting maternal physical and mental health. Although drugs and treatments are available to treat PND, early prevention and screening remain the best strategy. At present, there are different literatures on PND screening. Therefore, this study made a comprehensive summary and evaluation of relevant evidence, providing important evidence reference for clinical screening of PND and effective treatment. 


\section{PND screening is recommended throughout the perinatal period}

The level of evidence on the timing of PND screening is inconsistent. However, the results of the evidence summary highlight the importance of PND screening and suggest that screening should be performed throughout the perinatal period. Previous studies (27) have shown that the detection rates of PND fluctuates. Underwood et al. (28) found that $39 \%$ of women with prenatal depression showed PPD. On average, $47 \%$ of women with PPD also experience prenatal depression, which is associated with a 6.8 times increased risk of PPD (29). There is a correlation between prenatal depression and PPD. Previous depression or other psychological problems are the biggest risk factors for PND. Thus, it is necessary to strengthen the evaluation and management of the mental health status of perinatal women to achieve early detection and intervention.

Screening for depression should be done early in the prenatal period. The NICE has issued guidelines (17) suggesting that health-care providers should ask pregnant women on first primary care contact or at a doctor's appointment about depression, and use EPDS or Patient Health Questionnaire-9 (PHQ-9) items as part of the assessment. Related studies (22) have shown that most women experience a brief bout of depression during pregnancy and within a year of giving birth, but recover to their previously good levels of mental health.

Sixty to eighty percent of women will have "Baby Blues" 1-3 days after delivery, which are manifested as sudden mood swings, crying, irritability, and other negative emotions. The duration is short, and usually requires only social support and health education, and no medication (29,30). Screening for depression at this time would cause a large number of false positives, and as depression symptoms tend to stabilize 6 weeks after delivery, it would be reasonable to screen for PPD 6 weeks after delivery (27). More than $1 / 3$ of the articles included in this systematic review focused on PPD screening at 7-12 months (31). These studies suggest that the risk of PPD far exceeds the 4-6 weeks postpartum range suggested in the Diagnostic and Statistical Manual of Mental Disorders (DSM-5). This is important for the future development of PND screening strategies and specific treatment approaches.

\section{For high-risk maternal women, PND should be properly reassessed}

There are some risk factors in PND, like mental health problem, anxiety during pregnancy, life stresses, family and social supports, and socioeconomic factors (32-34). There is a lack of high-level evidence on the frequency of PND screening. According to the recommendations of the American College of Obstetricians and Gynecologists, proven screening tools should be used, and a depression screening should be performed at least once during pregnancy or postpartum (18). For women with high-risk factors, the frequency of psychological evaluations during pregnancy preparation and pregnancy should be increased as appropriate (19). Research has shown that risk factors for PND include a history of adverse pregnancy, pregnancy comorbidities, a history of depression, irregular antenatal visits, low income, domestic violence, being unmarried, and low social support (35). Prenatal and PPD risk factors are not the same. Thus, continuous attention and evaluations are necessary. When maternal women present with clinical symptoms, such as anxiety and depression, referral or a clinical interview is recommended for diagnosis, and repeat evaluations for PND should be performed. The JBI evidence summary indicates that when EPDS is $\geq 13$, reevaluations with the EPDS should be conducted after $2-4$ weeks (20).

For depression screening to be suitable in clinical practice, it must be simple and clear, with an acceptable risk of false positives and false negatives (36). Women are very concerned about the results of PND screenings, which may be related to the stigma associated with a diagnosis of depression, the referrals that a positive result may lead to, and the separation of mother and child. When the false positive rate of screening is high, this can also lead to expensive referral fees, unnecessary diagnostic evaluations and the possibility of misdiagnosed women being placed on antidepressants (24). Thus, the Lancet suggests that high-quality randomized controlled trials be conducted to undertake a comprehensive assessment of any potential adverse effects before the large-scale screening of depression is introduced (37).

Although medicines are not recommended during pregnancy, there is some evidence that they are effective. Brexanolone is proved to improve symptoms in three RCT. Further, Sertraline has also been reported to exert benefit role in reducing anxiety (38). Besides drugs, psychotherapy and social support therapy are also feasible methods to treat PND (36).

\section{Conclusions}

This study summarized the best evidence on the timing and 
frequency of screening for PND, and provided an evidencebased basis for determining the timing and frequency of PND screening. However, most of the articles included in this study were foreign, and consideration must be given to the different concepts and cultures in different regions and the different development levels of different countries. The application of the evidence should consider to combine the clinical conditions. Health-care professionals should fully consider the promotion and obstacles of applied evidence, patients' wishes, and other factors to develop personalized and local PND screening programs to improve the quality of maternal mental health care.

\section{Acknowledgments}

Funding: Science and Technology Development Funding of Nanjing Medical University (NMUB2019331).

\section{Footnote}

Conflicts of Interest: All authors have completed the ICMJE uniform disclosure form (available at https://dx.doi. org/10.21037/apm-21-2675). The authors have no conflicts of interest to declare.

Ethical Statement: The authors are accountable for all aspects of the work in ensuring that questions related to the accuracy or integrity of any part of the work are appropriately investigated and resolved.

Open Access Statement: This is an Open Access article distributed in accordance with the Creative Commons Attribution-NonCommercial-NoDerivs 4.0 International License (CC BY-NC-ND 4.0), which permits the noncommercial replication and distribution of the article with the strict proviso that no changes or edits are made and the original work is properly cited (including links to both the formal publication through the relevant DOI and the license). See: https://creativecommons.org/licenses/by-nc-nd/4.0/.

\section{References}

1. Van Niel MS, Payne JL. Perinatal depression: A review. Cleve Clin J Med 2020;87:273-7.

2. Silveira ML, Ertel KA, Dole N, et al. The role of body image in prenatal and postpartum depression: a critical review of the literature. Arch Womens Ment Health 2015;18:409-21.
3. Ogbo FA, Eastwood J, Hendry A, et al. Determinants of antenatal depression and postnatal depression in Australia. BMC Psychiatry 2018;18:49.

4. Nisar A, Yin J, Waqas A, et al. Prevalence of perinatal depression and its determinants in Mainland China: A systematic review and meta-analysis. J Affect Disord 2020;277:1022-37.

5. Azorin JM, Angst J, Gamma A, et al. Identifying features of bipolarity in patients with first-episode postpartum depression: findings from the international BRIDGE study. J Affect Disord 2012;136:710-5.

6. Dagher RK, Bruckheim HE, Colpe LJ, et al. Perinatal Depression: Challenges and Opportunities. J Womens Health (Larchmt) 2021;30:154-9.

7. Perra O, Phillips R, Fyfield R, et al. Does mothers' postnatal depression influence the development of imitation? J Child Psychol Psychiatry 2015;56:1231-8.

8. Sharkey KM, Iko IN, Machan JT, et al. Infant sleep and feeding patterns are associated with maternal sleep, stress, and depressed mood in women with a history of major depressive disorder (MDD). Arch Womens Ment Health 2016;19:209-18.

9. Wonch KE, de Medeiros CB, Barrett JA, et al. Postpartum depression and brain response to infants: Differential amygdala response and connectivity. Soc Neurosci 2016;11:600-17.

10. Tikotzky L. Postpartum Maternal Sleep, Maternal Depressive Symptoms and Self-Perceived Mother-Infant Emotional Relationship. Behav Sleep Med 2016;14:5-22.

11. Ghimire U, Papabathini SS, Kawuki J, et al. Depression during pregnancy and the risk of low birth weight, preterm birth and intrauterine growth restriction- an updated meta-analysis. Early Hum Dev 2021;152:105243.

12. Gong W, Jin X, Cheng KK, et al. Chinese Women's Acceptance and Uptake of Referral after Screening for Perinatal Depression. Int J Environ Res Public Health 2020;17:8686.

13. Lewis Johnson TE, Clare CA, Johnson JE, et al. Preventing Perinatal Depression Now: A Call to Action. J Womens Health (Larchmt) 2020;29:1143-7.

14. Hoffmann-Eßer W, Siering U, Neugebauer EAM, et al. Guideline appraisal with AGREE II: online survey of the potential influence of AGREE II items on overall assessment of guideline quality and recommendation for use. BMC Health Serv Res 2018;18:143.

15. The Joanna Briggs Institute (JBI). JBI grades of recommendation (EB/OL). (2017-07-15) (2020-04-26). 
Available online: http://joannabriggs.org/jbi-approach.html

16. Foster MJ, Shurtz S. Making the Critical Appraisal for Summaries of Evidence (CASE) for evidence-based medicine (EBM): critical appraisal of summaries of evidence. J Med Libr Assoc 2013;101:192-8.

17. NICE. Antenatal and postnatal mental health: Clinical management and service guidance. National Institute of Health and Clinical Excellence, London, 2016.

18. ACOG Committee Opinion No. 757: Screening for Perinatal Depression. Obstet Gynecol 2018;132:e208-12.

19. Psychosomatic Health Society, Committee of Women Mental Health Care, China Maternal and Child Health Association, China Preventive Medicine Association, Committee of Women Mental Health Care, China Maternal and Child Health Association. Consensus on maternal mental health management (2019). Chinese Journal of Women and Child Health Research 2019;30:781-6.

20. Minooee S. Evidence Summary. Antenatal: Psychosocial Assessment. The JBI EBP Database. 2021; JBI-ES-613-1.

21. O'Connor E, Senger CA, Henninger ML, et al. Interventions to Prevent Perinatal Depression: Evidence Report and Systematic Review for the US Preventive Services Task Force. JAMA 2019;321:588-601.

22. Biaggi A, Conroy S, Pawlby S, et al. Identifying the women at risk of antenatal anxiety and depression: A systematic review. J Affect Disord 2016;191:62-77.

23. Martínez-Borba V, Suso-Ribera C, Osma J. The Use of Information and Communication Technologies in Perinatal Depression Screening: A Systematic Review. Cyberpsychol Behav Soc Netw 2018;21:741-52.

24. Viguera A. postpartum unipolar major depression epidemiology clinical features assessment and diagnosis. UpToDate. Available online: https://www.wolterskluwer. com/en/solutions/uptodate

25. Lockwood CJ, Magriples U. Prenatal care second and third trimesters. UpToDate. Available online: https://www. wolterskluwer.com/en/solutions/uptodate

26. O'Connor E, Rossom RC, Henninger M, et al. Primary Care Screening for and Treatment of Depression in Pregnant and Postpartum Women: Evidence Report and Systematic Review for the US Preventive Services Task
Force. JAMA 2016;315:388-406.

27. Cena L, Mirabella F, Palumbo G, et al. Prevalence of maternal antenatal and postnatal depression and their association with sociodemographic and socioeconomic factors: A multicentre study in Italy. J Affect Disord 2021;279:217-21.

28. Underwood L, Waldie K, D'Souza S, et al. A review of longitudinal studies on antenatal and postnatal depression. Arch Womens Ment Health 2016;19:711-20.

29. Ceriani Cernadas JM. Postpartum depression: Risks and early detection. Arch Argent Pediatr 2020;118:154-5.

30. Manjunath NG, Venkatesh G, Rajanna. Postpartum Blue is Common in Socially and Economically Insecure Mothers. Indian J Community Med 2011;36:231-3.

31. Moraes GP, Lorenzo L, Pontes GA, et al. Screening and diagnosing postpartum depression: when and how?. Trends Psychiatry Psychother 2017;39:54-61.

32. Ryan D, Milis L, Misri N. Depression during pregnancy. Can Fam Physician 2005;51:1087-93.

33. Robertson E, Grace S, Wallington T, et al. Antenatal risk factors for postpartum depression: a synthesis of recent literature. Gen Hosp Psychiatry 2004;26:289-95.

34. Beck CT. Predictors of postpartum depression: an update. Nurs Res 2001;50:275-85.

35. Mersha AG, Abebe SA, Sori LM, et al. Prevalence and Associated Factors of Perinatal Depression in Ethiopia: A Systematic Review and Meta-Analysis. Depress Res Treat 2018;2018:1813834.

36. Yelland J, Sutherland G, Brown SJ. Postpartum anxiety, depression and social health: findings from a populationbased survey of Australian women. BMC Public Health 2010;10:771.

37. The Lancet. Screening for perinatal depression: a missed opportunity. Lancet 2016;387:505.

38. Viswanathan M, Middleton JC, Stuebe A, et al. AHRQ Comparative Effectiveness Reviews. Maternal, Fetal, and Child Outcomes of Mental Health Treatments in Women: A Systematic Review of Perinatal Pharmacologic Interventions. Rockville (MD): Agency for Healthcare Research and Quality (US), 2021.

(English Language Editor: L. Huleatt)
Cite this article as: Jia S, Zhi M, Liu J, Liu J, Jiang L, Zhu Y. Evidence summary on the timing and frequency of screening for perinatal depression. Ann Palliat Med 2021;10(10):10896-10903. doi: 10.21037/apm-21-2675 